\title{
MALIGNANT PHYLLODES TUMOR WITH SKIN ULCERATION AND NIPPLE AREOLA COMPLEX INVOLVEMENT: A CASE REPORT
}

\author{
Braja Mohan Mishraํㅜ, Malaya Krishna Nayak², Pratyusa Ranjan Bishi³, Jyotirmay Jena ${ }^{4}$
}

\section{HOW TO CITE THIS ARTICLE:}

Braja Mohan Mishra, Malaya Krishna Nayak, Pratyusa Ranjan Bishi, Jyotirmay Jena. "Malignant Phyllodes Tumor with Skin Ulceration and Nipple Areola Complex Involvement: A Case Report". Journal of Evolution of Medical and Dental Sciences 2014; Vol. 3, Issue 21, May 26; Page: 5658-5660,

DOI: $10.14260 /$ jemds/2014/2644

\begin{abstract}
Cystosarcoma phyllodes is a rare, predominantly benign tumor of the female breast, comprising less than $1 \%$ of all breast neoplasms. The incidence of malignancy in phyllodes tumor is even less, only $25 \%$ which usually does not ulcerate the skin or involve the nipple areola complex.1,2 Herein we report a case of 16years old girl with a right sided big malignant phyllodes tumor with nipple areola complex involvement and skin ulceration.
\end{abstract}

KEYWORDS: Breast, Phyllodes tumor, Malignant.

INTRODUCTION: Cystosarcoma phyllodes is an uncommon neoplasm exclusively occurring in the female breast, comprising $0.3-0.9 \%$ of all breast tumors. ${ }^{2,3}$ It is similar to fibroadenoma in structure, but distinguished from it histologically by large stromal cellularity. Its name is derived from the Greek words sarcoma, meaning fleshy tumor and phyllodes meaning leaf.3,4 Grossly the tumor looks like a large malignant sarcoma and in cut section takes leaf like appearance. Histologically displays epithelial cyst like spaces. ${ }^{5}$ Most of the cases are benign (60\%), 25\% are malignant and $15 \%$ are borderline. The malignant lesions rarely involve the skin and nipple areola complex. ${ }^{6}$

CASE REPORT: A 16year young girl presented with a slow growing right sided breast mass of duration of 2years with rapid progress during the last two months and skin ulceration. There was no complain of fever, bone pain, jaundice or any other swelling. On examination the patient was thin built, anemic. There was a mass of size $40 \times 30 \times 20 \mathrm{~cm}$ with variegated consistency, skin ulceration and nipple areola complex involvement [fig-1]. The skin over the remaining part was stretched and revealed dilated veins.

The breast and the mass were free from the chest wall. The other breast and both the axilla were normal. All the vitals and the blood parameters (except $\mathrm{Hb} \%$ ) were within the normal limit. FNAC from the affected breast reported as cystosarcoma phyllodes. After correction of anemia simple mastectomy was performed. The specimen [fig-3] sent for H. P. Study came out to be malignant variety of phyllodes tumor with more than $2 \mathrm{~cm}$ of tumor free margin. The postoperative period was uneventful and the patient was discharged on $10^{\text {th }}$ postoperative day with advice for periodical checkup.

DISCUSSION: Cystosarcoma phyllodes represents less than 1\% of the tumors of the breast.2, 3 It was first described by Muller in 1838. ${ }^{6}$ It is a non-tender, well circumscribed, mobile mass. Overlying skin may display a shiny appearance with engorged veins. Although benign tumors do not metastasize, they have tendency to grow aggressively and recur locally.4,6 Depending on the cellularity, invasiveness of the tumor, cytological atypia and mitotic count they are grouped into benign, 
malignant or borderline. ${ }^{4,5}$ Like other sarcomas the malignant lesions metastasize hematogenously and the common sites are lungs, skeletal system and the lever.5,6

For benign lesions excision with $1 \mathrm{~cm}$ negative margin is advocated. While for malignant variety mastectomy or breast conserving surgery with adequate free margin is advised. Adjuvant radiotherapy may be considered for high risk tumors. It thought to decrease the local recurrence rate but have no significant role in survival rate. As far as chemotherapy is concerned cyclophosphamide, doxorubicin, cisplatin and etopside have been used with limited success. Though the tumor contains estrogen, progesterone receptors, palliation with hormones has not been explored. ${ }^{6}$

CONCLUSIONS: Malignant phyllodes tumor is a rare tumor. There are only a few cases reported with skin and nipple areola complex involvement. Our case gives an insight into the natural history of phyllodes tumor, which may involve skin and nipple areola complex.

\section{REFERENCES:}

1. Kelly K Hunt, Lisa A Newman, Edward M Copeland, Kirby I Bland. The Breast-Schwartz's Principles of Surgery-9th edn -Mc Graw Hills-468(423-474).

2. Kelly K. Hunt, Marjorie C. Green, Thomas A. Buchholz- Diseases of the Breast-Sabiston Text book of Surgery19th edn -vol.1--Elsevier Publication-845(824-869).

3. Richard Sainsbury. The Breast: Bailey \& Love's short practice of surgery-26th edn- CRC Publications-807(798-822).

4. Susan C Lester. The Breast: Robbins \& Cotran Pathologic Basis of Diseases - $8^{\text {th }}$ ednELSEVIER=1092(1065-1096).

5. Dyer NH, Bridges EI, Taylor RS. Cystosarcoma phyllodes. Br J Surg 1966; 53:450-455.

6. Shwetank Prakash, Prince Raj. A Very Large Malignant Phyllodes Tumor with Skin Ulceration and Nipple Areola Complex Involvement. Indian J Surg. 2013 Feb; 75(1):39-42. Epub 2012 Apr 18.

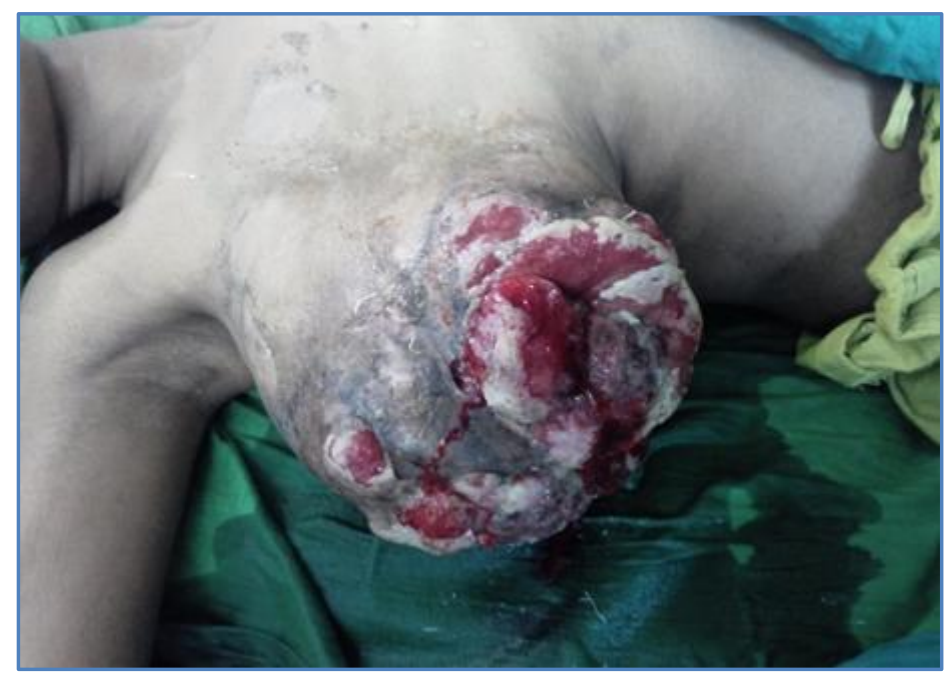

Fig. 1: Phyllodes tumor showing skin ulceration and nipple areola coplex involvement 


\section{CASE REPORT}

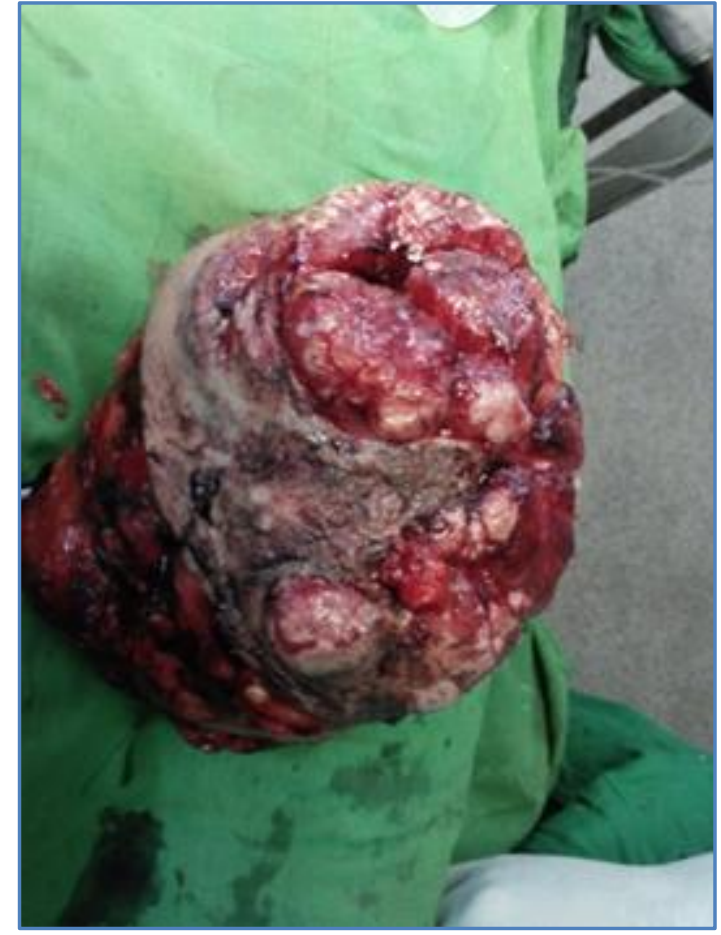

Fig. 2: Excised breast

\section{AUTHORS:}

1. Braja Mohan Mishra

2. Malaya Krishna Nayak

3. Pratyusa Ranjan Bishi

4. Jyotirmay Jena

\section{PARTICULARS OF CONTRIBUTORS:}

1. Professor, Department of Surgery, V.S.S. Medical College, Burla, Odisha.

2. Assistant Professor, Department of Surgery, V.S.S. Medical College, Burla, Odisha.

3. Post Graduate Student, Department of Surgery, V.S.S. Medical College, Burla, Odisha.

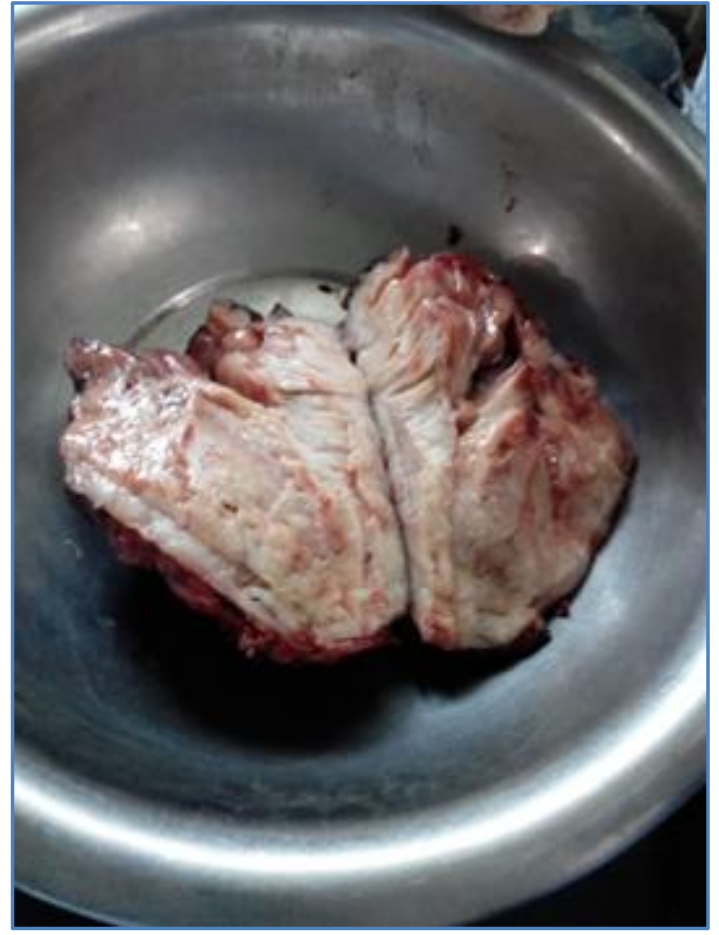

Fig. 3: cut section showing multiloculated cyst with necrosis
4. Post Graduate Student, Department of Surgery, V.S.S. Medical College, Burla, Odisha.

\section{NAME ADDRESS EMAIL ID OF THE CORRESPONDING AUTHOR:}

Dr. Malaya Krishna Nayak, Assistant Professor,

Department of Surgery,

V.S.S. Medical College, Burla, Odisha-768017.

Email: drmalayanayak@gmail.com

Date of Submission: 07/05/2014.

Date of Peer Review: 08/05/2014.

Date of Acceptance: 15/05/2014.

Date of Publishing: 20/05/2014. 